\title{
L'Oréal Group Strategic Analysis and Recommendations
}

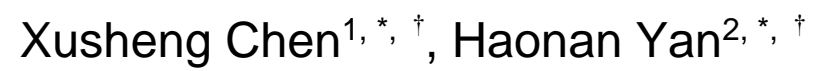 \\ ${ }^{1}$ Nanjing University of Science and Technology, Nanjing, China \\ 2University of Connecticut, Storrs, United states \\ *Corresponding author: xusheng425@foxmail.com,821747848@qq.com \\ These authors contributed equally.
}

\begin{abstract}
As the world's largest beauty group, the future development trend of L'Oréal Group will always affect many industries around the world. However, while facing the tremendous pressure of competition in the same industry, the pressure of the new crown epidemic has suddenly come, and the L'Oréal Group is facing an unprecedented crisis. After studying the 2020 strategy released by the L'Oréal Group, in order to study and analyze the future development strategy of the L'Oréal Group, and provide a theoretical basis for the development of the company, the author based on swot analysis and AHP analytic hierarchy process, through qualitative analysis and quantitative analysis, constructed Its AHP hierarchical structure model and weighted histogram, after studying the data, came to the conclusion that L'Oréal Group should adopt the WT strategy in the future, and put forward 6 related suggestions.
\end{abstract}

Keywords: Strategic, SWOT, AHP, Case Study

\section{Introduction}

\subsection{Overview}

As the world's largest cosmetics and beauty market, the United States can reach a terrifying retail sale of 90 billion yuan in $2020^{[3]}$. And this number has increased by nearly 45 percent in the past ten years. However, with the rapid development of the cosmetics industry, the risks of the entire industry have increased, because more people can make huge profits by creating false information. And social media has become a place where these counterfeit products are sold and promoted. With the development of modern technology, social media has become one of the indispensable tools in people's daily lives. US Customs and Border Protection data shows that counterfeit products now cause more than 75 million US dollars in losses to the cosmetics industry each year ${ }^{[1]}$.There are few studies on L'Oréal's advertising and marketing activities and consumer behavior in the North American market. Therefore, it is important to analyze how L'Oréal's advertising and marketing are accurate to target customers. In addition, L'Oréal's products involve different target customer groups, and the most direct division is the income gap. Therefore, it is necessary to analyze the advertising content and customer perception of L'Oréal, which is precisely the content that is lacking in the existing research. How a brand builds a brand image to establish brand loyalty is the first issue that large companies need to consider. L'Oréal Group is no exception. In view of the existing bad reviews in the market, how can L'Oréal improve to expand customer preference and build brand loyalty It is one of the first tasks that L'Oréal needs to consider at present.

\subsection{Different perspectives}

Different scholars have different opinions on how advertising affects the market. According to Stephen F. Hamilton ${ }^{[4]}$, the main purpose of advertising is the effect of the advertising itself. However, there are two schools of advertising how to express its own effects in the market. According to Stephen F. Hamilton ${ }^{[4]}$, one side of thought expressed in the contributions of Kaldor (1950) and Bain (1956) is the view that advertising plays a compelling role first and foremost. In this view, advertising increases product differentiation and deters market entry by adding recognition and prestige to advertised products, thereby increasing the market power of companies that sell and price advertised 
products. A second school of thought, formalized by Ozga (1960), Stigler (1961), Telser (1964) and Nelson $(1970,1974)$, points out the important role that advertising plays in providing information on prices and quality of the product. Informational advertising reduces the costs associated with consumer search and facilitates product substitution, resulting in lower prices and better market performance.

According to Hall Harris ${ }^{[5]}$, advertising itself is a tool in the market. Advertising can effectively display services and products, and can provide consumers with effective company data and information. Advertising greatly increases the sales of products. Once consumers understand a company's products and services, they are more likely to go out and buy, especially when the advertising attracts them to try and experience for themselves. Through e-commerce and social media, companies have now greatly expanded their reach and can conduct real transactions with consumers anywhere in the world. Hall Harris also believes that advertising makes market classification more diversified, because advertising and the revenue it brings are inseparable. Companies need to make their advertisements as possible as possible to target the correct audience, so the advertising will become more targeted. The market has therefore also been segmented. Finally, advertising also allows companies to effectively establish a recognizable brand. Effective advertising can help companies quickly establish unique advantages in the market. Advertising strategy is already one of the indispensable factors in every company.

\subsection{Conclusion}

In order to understand the reasons why L'Oréal Group has become the world's largest cosmetics company, especially its success in the North American market, this article will analyze its advertising in the North American market and consumer behavior patterns through qualitative research. The author takes L'Oréal's advertising and marketing activities in North America as the research object, using literature review, content analysis, data analysis, questionnaire surveys and other methods, as well as the successful experience in marketing campaigns. Through the study of brand marketing of L'Oréal, the article intends to reach the main strategies that L'Oréal used, how it can improve to earn the better reputation, how these can be implemented to other industries.

\section{Data and Method}

\subsection{Data}

Founded in 1907, L'Oréal is the world's largest cosmetics company, headquartered in France. In 2017, L'Oréal's sales reached 26.02 billion euros $/+0.7 \%$, net profit deducting 3.748 billion euros/ $+15.3 \%$, and the world's largest market share ${ }^{[1]}$. L'Oréal had its first in the hair-color sector, but this company soon branched out into different cleansing and beauty products. L'Oréal currently markets around 497 patents ${ }^{[2]}$ and thousands of various products in all spheres of the women's sector: Hair color, permanents, hair styling, structure and skin care, cleansers, makeup, and fragrance. This organization's products are seen at a broad variety of distribution channels, from fabric salons and perfumeries to hyper-and supermarkets, healthy/beauty outlets, pharmacies, and through communications.

L'Oréal's idea is undoubtedly perfect. But how to expand her advantage and maintain her advantage in the entire industry. Commercial advertising is undoubtedly an indispensable part. L'Oréal can export different cultures and ideas that its brand wants to express to customers through advertising. For example, many advertising retailers now attract customers by encouraging and supporting women in their advertisements, so that women as a group can spend more in the cosmetics industry.

Although advertising can help each company better achieve its own marketing goals, we may as well see some problems from many advertisements. Nowadays, the common problem of cosmetics advertising is that when a model uses the same products as the customer, but with the help of a more professional shooting location and professional background work, the effect displayed by the model 
is completely different from the effect of ordinary customers. of. So many times, when customers find such problems, they will think about whether the various types of makeup products sold by cosmetics merchants are so well displayed in the advertisements, or whether they are simply to attract customers and consume high photography expenses. Create pictures of fake models.

\subsection{Method}

\subsubsection{SWOT Analysis}

SWOT analysis method is a method of enterprise internal analysis, which is based on the established internal conditions of enterprises to find out the advantages, disadvantages and core competitiveness of enterprises. Among them, S stands for strength (advantage), W stands for weakness (weakness), 0 stands for opportunity (opportunity), T stands for threat (threat), in which $\mathrm{S}$ and $\mathrm{W}$ are internal factors, and 0 and $\mathrm{T}$ are external factors. According to the. concept of enterprise competitive strategy, strategy should be an organic combination of what an enterprise can do (i.e., strengths and weaknesses of an organization) and what can be done (i. e., opportunities and threats to the COV-19).

\subsubsection{AHP Analysis}

The method of solving the weight of the brand competitiveness index adopts the analytic hierarchy process (AHP), and quotes the nine-level scaling method proposed by Professor SATTY to quantitatively evaluate each level index, that is, to compare the importance of the index item by item to the matrix sequence constructed at each level and assign values from 1 to 9 to complete the index parameter matrix of each level of brand competitiveness. According to the nine-level scaling method, select relevant brand research scholars, compare the indicators of each level in the indicator system, and assign values to each indicator. A represents the target, ai and aj represent factors, and ai aj represents the relative importance of ai to aj. It is necessary to establish a total of nine judgment matrices Aij (i, j=1, 2, .., n).

According to the square root method, nine judgment matrices are established, based on

The calculation steps are solved separately to obtain the Weights. The calculation steps:

Step 1: Multiply the elements in the judgment matrix by rows

The criterion for judging passing the consistency ratio test is based on the size of the CR value: if $\mathrm{CR} \leq 0.1$, the established target matrix passes the test; if $\mathrm{CR}>0.1$, the test fails.

By checking the consistency of nine judgment matrices, the maximum value of $\mathrm{CR}$ is $\mathrm{XX}$, all of which are less than 0.1 . Therefore, the consistency check is successful, and the weight values of each indicator are shown in Table X.

Step 1: Multiply the elements in the judgment matrix by rows

$$
\mu_{i}=\prod_{j=1}^{n} a_{i j}
$$

Step 2: the product of the multiplication is divided into the nth power

$$
\mu_{i}=\sqrt[n]{\mu_{i j}}
$$

Step 3: Normalize the square root value, namely Get the eigenvector $\beta$

$$
\beta=\frac{\mu_{i}}{\sum_{i=1}^{n} \mu_{i}}
$$


Volume 16 (2021)

Step 4: Calculate the largest eigenvector $\lambda$ max of the judgment matrix

$$
\lambda_{\max }=\sum_{i=1}^{n} \frac{(A \beta)_{i}}{(n \beta)_{i}}
$$

Step 5: Calculate the consistency index CI

$$
C I=\frac{\lambda_{\max }-n}{n-1}
$$

Step 6: Calculate the consistency ratio CR

$$
C R=\frac{\mathrm{CI}}{\mathrm{RI}}
$$

The criterion for judging passing the consistency ratio test is based on the size of the CR value: if $\mathrm{CR} \leq 0.1$, the established target matrix passes the test; if $\mathrm{CR}>0.1$, the test fails.

By checking the consistency of nine judgment matrices, the maximum value of $\mathrm{CR}$ is $\mathrm{XX}$, all of which are less than 0.1 . Therefore, the consistency check is successful, and the weight values of each indicator are shown in Table X.

$$
B=\sum_{j=1}^{m}\left(\sum_{i=1}^{n} A_{i} \cdot \omega_{i}\right) \cdot X_{j}
$$

In the formula, B represents the final score of the model; Ai represents the score of the third level; $\omega$ i represents the weight of the third level; $\mathrm{Xj}$ represents the weight of the second level; $\mathrm{n}$ represents the frequency of the third level; $\mathrm{m}$ is the frequency of the first level indicator. According to the established indicator system, formulate the detailed rules for the assignment of the indicator system. Each indicator value is a percentage system, and the value is assigned based on the average value of experts and questionnaires. Then, according to the calculation formula, the comprehensive score of different brands is calculated, so as to compare the different brands in the market. Competitive advantage in the industry.

The specific steps of the SWOT-AHP method are as follows:

1. Identify problems at the target level and analyze their strengths, weaknesses, opportunities and threats

SWOT analysis;

2. Construct an AHP evaluation index system based on the results of SWOT analysis and calculate the weight of each level of index group;

3. Carry out a consistency check;

4. Calculate the comprehensive weight of each indicator;

5. Calculate the comprehensive strength of each index according to the comprehensive strength score of experts;

6. Calculate the total strength of each factor to limit the position of the four images, establish a strategic quadrilateral, and improve Development strategy 


\section{Result and Discussion}

\subsection{SWOT analysis}

L'Oreal is a major player in the cosmetics and beauty industry. The company has a wide portfolio consisting of makeup, hair and skin products. It also has a diversified portfolio that allows it to offer both luxurious and inexpensive products. By doing so the company is able to appeal to various market segments based on income and consumer preference and in the process increase its market share in the industry as a whole. The following is a SWOT analysis of the company:

Strengths

Diversity of the products and Organic products

L'Oréal has such a massive market share in the beauty world in part because of the variety of products under its corporate umbrella. In the North American market it is hard to walk through the makeup or beauty isles in stores without coming across a variety of L'Oreal products. Having such a wide variety of products in the market is a massive strength as it increases the reach of the company. It is a strategic advantage that allows the company to appeal to various consumer segments by attending to their exact needs with its wide range of products. The company has a market share of $24 \%$ in North America with sales averaging at about $\$ 28.9$ billion on an annual basis. It also has about 39 beauty brands under its umbrella including Urban Decay, Garnier, Maybelline, Body Shop, Essie and Lancome. Its skincare and hair care brands include La Roche Posay, Pureology and Skin Ceuticals. The idea of organic products is gaining a lot of traction in the beauty world. People want to look as good as possible without using products that contain toxic chemicals that potentially harm their bodies. L'Oreal boasts of an array of products that use natural ingredients. Despite the use of natural ingredients being more expensive L'Oreal has been able to incorporate these ingredients into its products and in the process appeal to a more aware consumer base.

Research and development

L'Oreal has managed to create a name for itself as a market leader when it comes to research and development. The research and development acumen of the company can be attributed to the wide array of products under its corporate portfolio ${ }^{[6]}$. L'Oreal works extensively with dermatologists and cosmetologists in order to ensure that its products are not only top of the line but also offer the highest utility possible to the customers. The company has over 4,000 people working in its research and innovation centers around the world on a daily basis. The main task of these 4,000 people is development and improvement of products and discovery of entirely new product formulas. The company also has a total of 21 research centers across the globe and 497 registered patents. The large number of patents is evident of the commitment of the organization to research and development.

Brand value and Marketing

L'Oreal is one of the most valuable brands in the cosmetics industry. In 2020 the company had a market capitalization of about $\$ 162.5$ billion. It is also ranked at number 30 in the list of the world's most valuable brands in $2020^{[7]}$. Having such a renowned brand is a major strength of the company. It means that the company has influence in the industry. It also increases the degree to which customers trust products associated with the company. L'Oréal is famous for its above the line marketing campaigns for each product under its greater portfolio. Each brand is also known for elements of integrated marketing communications ${ }^{[8]}$. Such a heavy investment in marketing means that its products are more visible compared to other relatively smaller brands in the market. It also means that each product receives a tailored marketing campaign that specifically targets the desired market segment. The company is also very good when it comes to point of purchase marketing. Essentially there is a lot of investment in strategies that are meant to persuade as many people as possible to purchase its products. This strategy is a massive advantage that has allowed the company to increase its sales over time and maintain a strong sense of market dominance. It also allows the company to reach out to different market segments and create campaigns that give each product a unique sense of identity that further allows it to stand out.

Weaknesses 
Organizational Redundancy and Poor Communication

Despite having a massive product range, the company has limited categories of divisions. An example of this is the fact that the company employs over 60,000 people in customer care, product development and manufacturing divisions ${ }^{[9]}$. This leads to excessive human capital and relatively slow response rates. The limited divisions within the company are associated with massive redundancies in key areas of functioning such as marketing specific products to niche consumers in the North American market.

Growth Saturation and Peer Competition

L'Oreal operates in one of the most competitive markets and industries on the planet. In North America alone there are numerous new brands in skin care and hair care coming up every day. The company finds itself having to compete with these newcomer brands on a rather continuous basis. In addition to competing with the major players in the industry L'Oreal also has to compete with relatively smaller players that make use of celebrities and their social media power in order to market their products. This has led to the company experiencing elements of growth saturation in key segments such as skin care.

Declining profits

L'Oreal has managed to build a name for itself by focusing heavily on research and development. This element of expenditure has led to the company gaining the trust of the consumers in the market. However, it is a continuous expense that eats away at the profit margins of the company on a continuous basis. Such a focus on research and development leads to a ballooning of operational costs and a decline in the profitability of the company ${ }^{[10]}$. The focus on research and development can, therefore, be thought of as both a strength and weakness of the company.

Supplier Power

The company depends heavily on its suppliers to ensure smooth operations. This means that the suppliers have a lot of power when it comes to the operations of the company. Overdependence on suppliers is a weakness as it predisposes the company to potential issues in its greater supply chain especially in the event that there is a disagreement with a major supplier. The lack of a proper balance in the relationship with suppliers is a huge weakness especially for a company that relies heavily on continuous operation and availability of products in the market.

Opportunities

Focus on active health products and high-end products

L'Oréal Group released its financial report for the first half of $2021^{[11]}$. During the period, sales increased by $20.7 \%$ year-on-year to 15.19 billion euros, and operating profit increased by $26.8 \%$ yearon-year to 2.99 billion euros, resuming the growth rate before the epidemic.In the first half of the year, the sales of L'Oréal Group's professional products division increased $41 \%$ year-on-year to 1.779 billion euros, the high-end cosmetics division sales increased $28.1 \%$ year-on-year to 5.472 billion euros, and the active health cosmetics division sales increased $37.5 \%$ year-on-year to 1.982 billion euros. The mass cosmetics division grew less than expected, with sales increasing by $6.3 \%$ year-onyear to 5.963 billion euros. Sales in the North American market increased by $23.2 \%$ year-on-year to 3.766 billion euros. It can be seen that the market for active health products and high-end products is the future development opportunity of L'Oréal Group.

High-tech products generate high profits

Accelerating the integration of technology and beauty, attracting users with freshness and experience. Procter \& Gamble recently launched the world's first spotting beauty device. L'Oreal also launched La Roche-Posay's "Effica Artificial Intelligence Acne Detection Application". It can detect the health of the skin online, and then the system will automatically recommend the corresponding products for consumers ${ }^{[12]}$.

Blue sea market

Entry into the cosmetics and skin care market by sub-category. In addition to women's skin care, the market segments of men's, children's and the elderly's skin care products are also becoming more mature. According to the report, the online transaction volume of men's care reached 4.02 billion 
yuan in 2019 , a year-on-year increase of $24.5 \%^{[13]}$. At present, the male market has not really exploded, and L'Oreal can seize this opportunity to expand the male skin care business line.In addition, with the upgrading of consumption and the rise of awareness of maintenance, skin care products for children and the elderly are also developing rapidly.

Private customization concept

Layout a precise skin care model tailored to the skin. With the further popularization of beauty knowledge, consumers pay more attention to the ingredients in skin care products. At the beginning of 2017, the L'Oréal Group acquired three cosmeceutical skin care brands CeraVe, AcneFree and Ambi under the Canadian Valeant company for US $\$ 1.3$ billion, breaking the record of acquiring IT Cosmetic for US $\$ 1.2$ billion in July 2016 and combining these three brands. Incorporated into the active health department of the group. At the same time, tailor-made precision skin care has also become a new trend, and high-end tailor-made skin care brand Xiuli can be loved by the medical beauty industry. L'Oréal can take this opportunity to further accelerate the development of its active health brands ${ }^{[14]}$.

Southeast Asian market

L'Oréal has reached a strategic cooperation with Lazada, the largest e-commerce platform in Southeast Asia under Alibaba, and has achieved next-day delivery in important cities in Southeast Asia. In addition to L'Oreal, global giants such as Shiseido and Estee Lauder have also paid more attention to the Southeast Asian market.According to the report, Southeast Asia is included in the "future market" that the global cosmetics industry will focus on. In 2018, the beauty market in Southeast Asia reached 164 billion yuan and is expected to reach 304.8 billion yuan in 2025, with a compound annual growth rate (CAGR) of $9.3 \%$, which is higher than the $8.23 \%$ compound annual growth rate of cosmetics in the Chinese market in the next five years ${ }^{[15]}$.

Threats

competitors

Shiseido and Estee LauderDespite both have a massive product range. Estee Lauder is suitable for female consumers between the ages of 20 and $50^{[16]}$; the product value is high, the product service is professional, the effect is good, and the research and development, product innovation is emphasized; the high-end positioning and the scarcity route; the wide range of people; the price is popular, and the price is high; the brand High visibility; easy to buy.

Shiseido has great brand influence; deep corporate culture; fast technology research and development; large investment in advertising; differentiated core products; strong market analysis and adaptability.Target customers: high-end female customers pursuing fashion Key points of strategic control:Invest in research and development of innovative products ,Advanced marketing and sales strategy ,Provide sales services to business leaders, Diversified channels and geographic scope.The US cosmetics market has boomed in the past five years. Many celebrities have launched their own successful brands, such as singer Rihanna's Fenty Beauty series or Kylie Jenner's Kylie Cosmetics. . They use their huge fan base to quickly create brand effects. For these fast-growing emerging brands, it is difficult for the L'Oréal Group to compete with them through traditional model. COV-19 threat

The uncertainty of the development of the COV-19 epidemic has brought difficulties to the further decision-making of the L'Oréal Group ${ }^{[15]}$. Factory manufacturing will be interrupted due to the epidemic. Last year on July 30, L'Oréal Group announced the first half of 2020 financial report, showing that the group's semi-annual sales performance fell for the first time in the past five years. L'Oréal's total sales in the first half of this year was 13.07 billion euros (approximately RMB 108.5 billion), a year-on-year decrease of $11.7 \%$; net profit was 1.82 billion euros (approximately RMB 15.1 billion), a year-on-year decrease of $21.8 \%{ }^{[17]}$.

Product safety

The results of an investigation report recently released by the Canadian Environmental Protection Organization show that the heavy metal components lurking in cosmetics are harmful to the human body. It is understood that in the 49 internationally renowned brands of cosmetics tested this time, 
almost every one contains harmful substances such as arsenic, cadmium, lead, mercury, beryllium, nickel, selenium and thallium. The tested products come from international first-line brands such as Clinique and L'Oreal ${ }^{[1]}$.

\subsection{AHP analysis}

L'Oréal Group Development Based on AHP-SWOT Analysis Development strategy:

Hierarchical structure model construction L'Oréal Group brand strategy analysis AHP evaluation index.

The hierarchical structure model of the standard system is shown in Figure 1

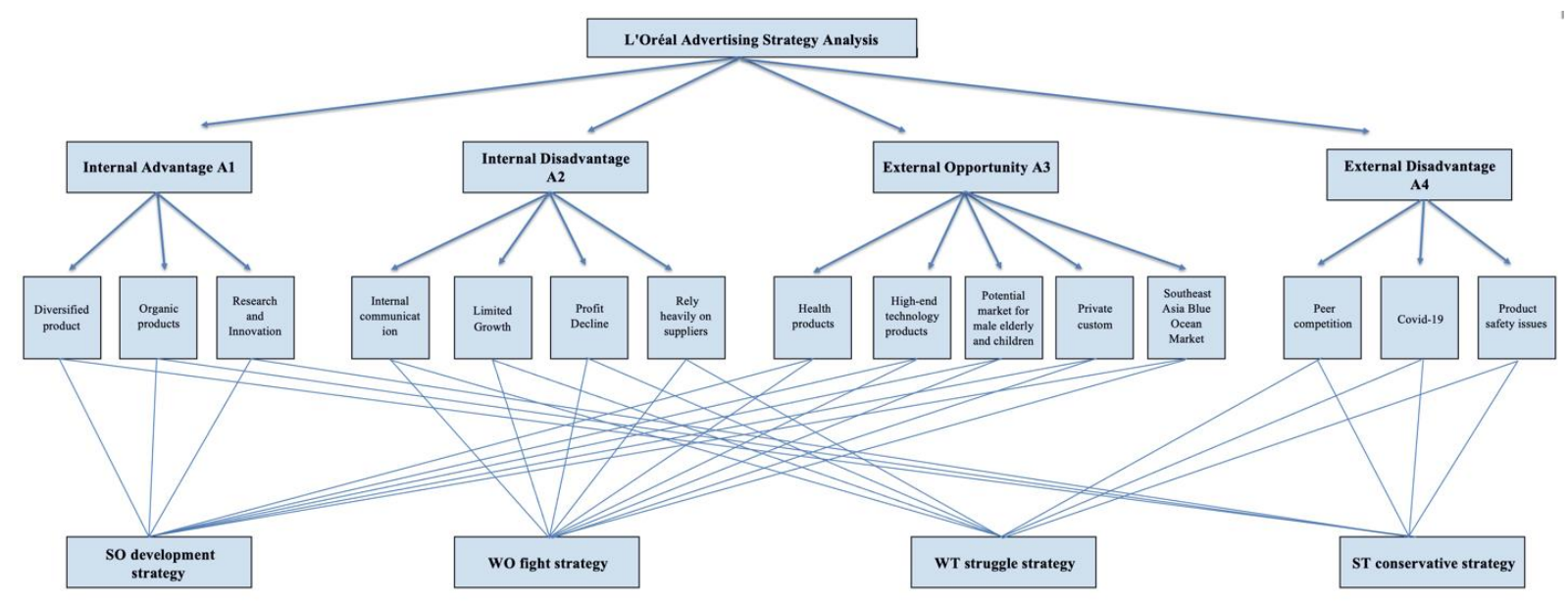

Figure 1. AHP hierarchy model

For the first-level indicators, namely advantage $\mathrm{S}$, disadvantage $\mathrm{W}$, opportunity $\mathrm{O}$ and threat $\mathrm{T}$, after scoring, the matrix SWOT is obtained:

Table 1. SWOT judgment matrix

\begin{tabular}{ccccccccc}
\hline & $\mathrm{S}$ & $\mathrm{W}$ & $\mathrm{O}$ & $\mathrm{T}$ & Feature vector & Weights & Maximum eigenvalue & $\mathrm{CI}$ \\
\hline $\mathrm{S}$ & 1 & 0.333 & 0.2 & 0.143 & 0.25 & $6.250 \%$ & & \\
$\mathrm{~W}$ & 3 & 1 & 0.6 & 0.429 & 0.75 & $18.750 \%$ & 4 & 0 \\
$\mathrm{O}$ & 5 & 1.667 & 1 & 0.714 & 1.25 & $31.250 \%$ & & \\
$\mathrm{~T}$ & 7 & 2.333 & 1.4 & 1 & 1.75 & $43.750 \%$ & & \\
\hline
\end{tabular}

For each secondary index in the advantage S: S1 diversified product advantage, S2 organic product advantage, $\mathrm{S} 3$ research and innovation advantage, score, and get the $\mathrm{S}$ matrix, as shown in Table 1.

Table 2. Strength judgment matrix

\begin{tabular}{cccccccc}
\hline & S1 & S2 & S3 & Feature vector & Weights & Maximum eigenvalue & CI \\
\hline S1 & 1 & 3 & 0.429 & 0.818 & $27.273 \%$ & & \\
S2 & 0.333 & 1 & 0.143 & 0.273 & $9.091 \%$ & 3 & 0 \\
S3 & 2.333 & 7 & 1 & 1.909 & $63.636 \%$ & & \\
\hline
\end{tabular}

For each of the secondary indicators in the disadvantage W: W1 internal communication, W2 growth is limited, W3 profit decline, W4 is heavily dependent on suppliers, scored, and W matrix is obtained, as shown in Table 2. 
Table 3. Weakness judgment matrix

\begin{tabular}{ccccccccc}
\hline & W1 & W2 & W3 & W4 & Feature vector & Weights & Maximum eigenvalue & CI \\
\hline W1 & 1 & 1.667 & 5 & 0.714 & 1.562 & $31.250 \%$ & & \\
W2 & 0.6 & 1 & 3 & 0.429 & 0.937 & $18.750 \%$ & 4 & 0 \\
W3 & 0.2 & 0.333 & 1 & 0.143 & 0.312 & $6.250 \%$ & \\
W4 & 1.4 & 2.333 & 7 & 1 & 2.187 & $43.750 \%$ & & \\
\hline
\end{tabular}

For each secondary indicator in Opportunity $\mathrm{O}$ : $\mathrm{O} 1$ active health products, $\mathrm{O} 2$ high-tech innovative products, $\mathrm{O} 3$ potential markets for the elderly and children, $\mathrm{O} 4$ private customization, O5 Southeast Asian blue ocean market, score, and get the O matrix, as shown in Table 3.

Table 4. Opportunity judgment matrix

\begin{tabular}{cccccccccc}
\hline & O1 & O2 & O3 & O4 & O5 & Feature vector & Weights & Maximum eigenvalue & CI \\
\hline O1 & 1 & 1.75 & 1.4 & 1 & 7 & 1.458 & $29.167 \%$ & & \\
O2 & 0.571 & 1 & 0.8 & 0.571 & 4 & 0.833 & $16.667 \%$ & & \\
O3 & 0.714 & 1.25 & 1 & 0.714 & 5 & 1.042 & $20.833 \%$ & 5 & 0 \\
O4 & 1 & 1.75 & 1.4 & 1 & 7 & 1.458 & $29.167 \%$ & & \\
O5 & 0.143 & 0.25 & 0.2 & 0.143 & 1 & 0.208 & $4.167 \%$ & & \\
\hline
\end{tabular}

For each of the secondary indicators in Challenge T: T1 is under pressure from the same industry, T2 is affected by the epidemic situation in the new museum, and T3 is product safety issues, score them and obtain the T matrix, as shown in Table 4

Table 5. Threat judgment matrix

\begin{tabular}{cccccccc}
\hline & T1 & T2 & T3 & Feature vector & Weights & Maximum eigenvalue & CI \\
\hline T1 & 1 & 0.556 & 5 & 1 & $33.333 \%$ & & \\
T2 & 1.8 & 1 & 9 & 1.8 & $60.000 \%$ & 4 & 0 \\
T3 & 0.2 & 0.111 & 1 & 0.2 & $6.667 \%$ & & \\
\hline
\end{tabular}

Multiply the weights of the single ranking of each three-level indicator by the weights of the judgment matrix between the four first-level indicators to obtain the total ranking weight of each secondary indicator, and perform the ranking. The calculation results are shown in Table 5.

Table 6. Total judgment matrix

\begin{tabular}{ccccc}
\hline Criterion layer & Weights & Index layer & Weights & Total Weights \\
\hline $\mathrm{S}$ & $6.250 \%$ & $\mathrm{~S} 1$ & $27.273 \%$ & 0.017045625 \\
& & $\mathrm{~S} 2$ & $9.091 \%$ & 0.005681875 \\
$\mathrm{~W}$ & $\mathrm{~S} 3$ & $63.636 \%$ & 0.0397725 \\
& $18.750 \%$ & $\mathrm{~W} 1$ & $31.250 \%$ & 0.05859375 \\
& & $\mathrm{~W} 2$ & $18.750 \%$ & 0.03515625 \\
$\mathrm{O}$ & $\mathrm{W} 3$ & $6.250 \%$ & 0.01171875 \\
& \multirow{3}{*}{$31.250 \%$} & $\mathrm{~W} 4$ & $43.750 \%$ & 0.08203125 \\
& & O1 & $29.167 \%$ & 0.091146875 \\
& & O2 & $16.667 \%$ & 0.052084375 \\
& & O3 & $20.833 \%$ & 0.065103125 \\
$\mathrm{~T}$ & & O4 & $29.167 \%$ & 0.091146875 \\
& \multirow{3}{*}{$43.750 \%$} & O5 & $4.167 \%$ & 0.013021875 \\
& & T1 & $33.333 \%$ & 0.145831875
\end{tabular}


Figure 2 shows that in the total ranking weights of each first-level indicator: the weight within the group $\mathrm{S}$ of the advantage factor is 0.0625 , the weight within the group $\mathrm{W}$ of the disadvantage factor is 0.1875 , the weight within the group $\mathrm{O}$ of the opportunity factor is 0.3125 , and the weight within the group $\mathrm{T}$ of the challenge factor is 0.4375 . That is, the total ranking weight of the challenge factor $\mathrm{T}$ and the opportunity factor $\mathrm{O}$ is larger, and the weight of the disadvantage factor $\mathrm{W}$ and the advantage factor $\mathrm{S}$ is relatively small. Among the total ranking weights of each secondary indicator, the three most weighted indicators are: horizontal competition pressure T1 (0.145831875), the impact of the new museum epidemic T2 $(0.2625)$, active health products O1 and private customization O4 (0.091146875); The three indicators with smaller weights are the advantages of S1 diversified products: (0.017045625), the advantage of S2 organic products (0.005681875), and the profit decline W3 (0.015 5).

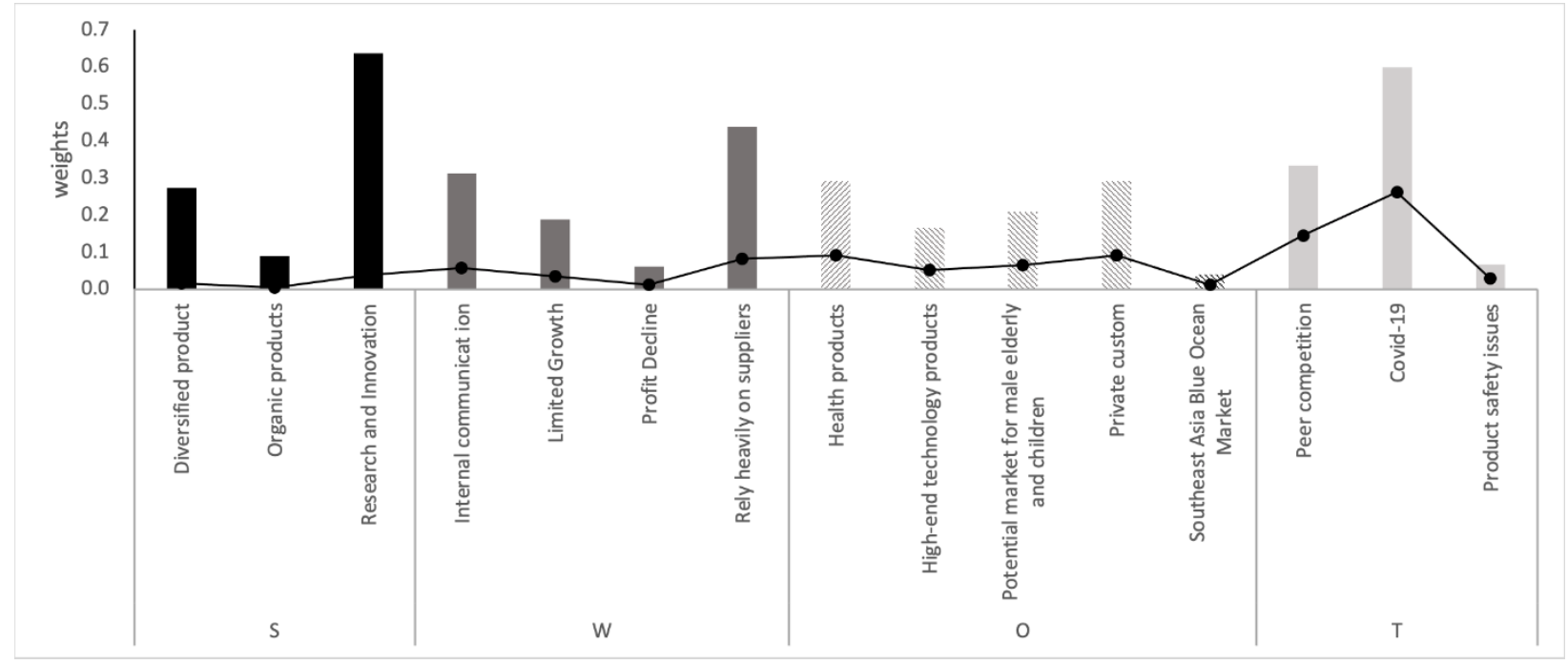

Figure 2. Weighted histogram

\section{L'Oréal Group Strategic Analysis}

Through SWOT-AHP analysis of L'Oréal Group's brand strategy, it is concluded that threat factors and opportunity factors have a larger weight, while disadvantages and advantages have a smaller weight. According to the L'Oréal Group's brand strategy quadrilateral, it can be seen that the center of gravity is in the third quadrant, indicating that L'Oréal Group should adopt a conservative strategy of WT. It is a conservative strategy. Companies should avoid this situation as much as possible. Once faced, companies need to minimize losses or quickly make up for disadvantages to avoid threats. 


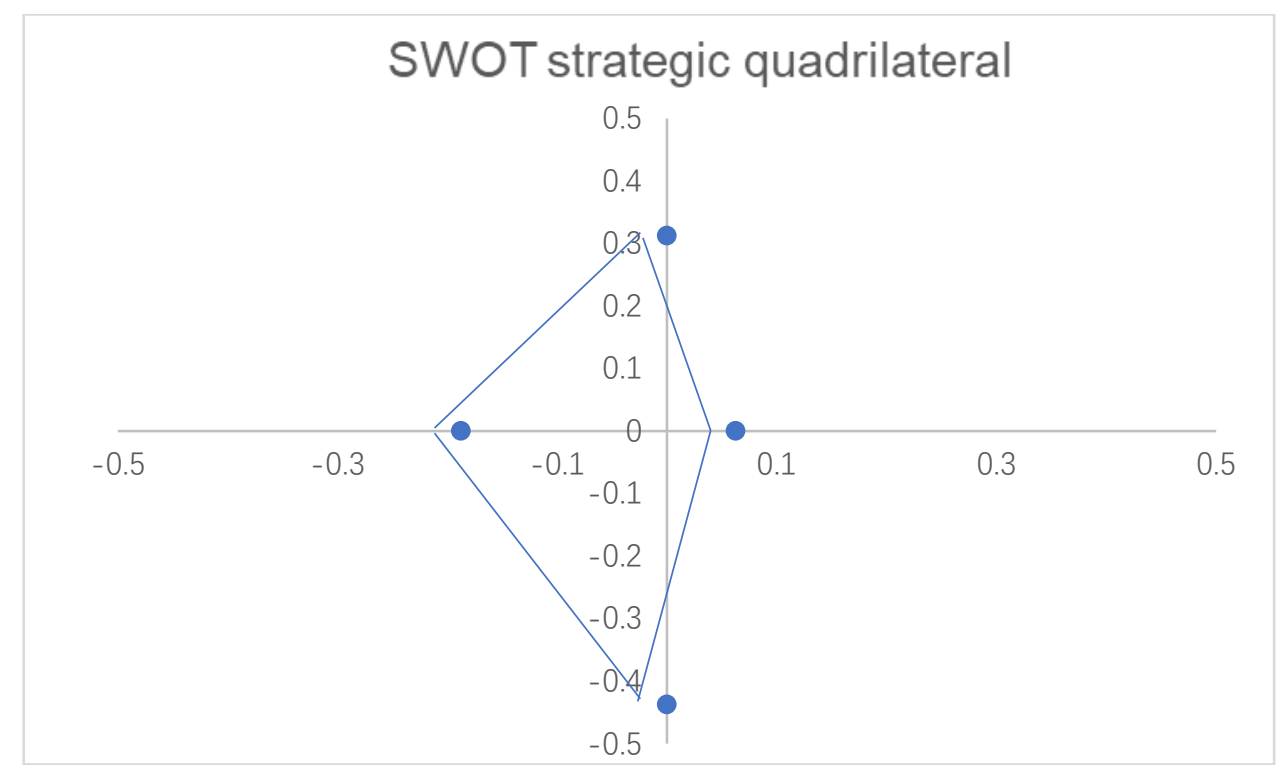

Figure 3. SWOT analysis

Calculate the total intensity of each first-level index (add up the intensity of each index in the group), and the calculation results are as follows:

Total strength of superiority $\mathrm{S}=\sum \mathrm{Si} / \mathrm{ns}=0.0625$

Total strength of disadvantage $\mathrm{W}=\sum \mathrm{Wi} / \mathrm{nW}=-0.1875$

Total opportunity strength $\mathrm{O}=\sum \mathrm{Oi}=$ no $=0.3125$

Total threat strength $\mathrm{T}=\sum \mathrm{Ti}=$ ot $=-0.4375$

Put the calculated total intensity of the 4 first-level indicators in the four-dimensional coordinates. Find and connect them in the S, W, O, and T coordinates, and calculate the strategy four. The center of gravity of the polygon is $\mathrm{P}(-0.0417,-0.0417)$, where $\mathrm{P}$ is the strategy

The coordinates of the center of gravity are marked in the quadrants, depicting a strategic quadrilateral,

Strategic azimuth $\theta=\arctan (\mathrm{Y} / \mathrm{X}) \approx 45^{\circ}$

Strategic positive strength $\mathrm{U}=\mathrm{O} \times \mathrm{S}=0.01953$

Strategic negative strength $\mathrm{V}=\mathrm{T} \times \mathrm{W}=0.08203$

Strategic strength coefficient $\mathrm{p}=\mathrm{U} /(\mathrm{U}+\mathrm{V})=0.1923$

\section{Conclusions}

The article first uses the SWOT analysis method to analyze the internal and external environmental factors such as the advantages and disadvantages of L'Oréal Group's own development, the opportunities and threats it faces, and then uses the analytic hierarchy process to quantify various indicators. SWOT analysis is used to determine the weight of each indicator. The results show that disadvantages and opportunities have a higher weight in the development of L'Oréal Group. Relying heavily on suppliers, the weight is the highest in the analysis of disadvantages, and the impact of COV-19 has the highest weight in the threat analysis. Using the four-quadrant analysis method, it is concluded that the enterprise should choose WT strategy as its development strategy in 2022. Finally, based on the results of the AHP-SWOT analysis, the next development strategy of the L'Oréal Group is proposed to provide a reference for accelerating the development of the beauty industry and advocating the development of environmental protection.

1. Flexible analysis and response to changes in policies and forms in various countries and regions, and timely adjustment of product production and marketing policies: 
2. Develop new market segments and achieve the complementarity of high-profit markets and high-potential markets

3. Use the four-quadrant analysis method to study the company's current product status and innovatively design the future product matrix

4. Adjust the upstream and downstream relationship of the industrial chain, avoid strong dependence on the supply chain/suppliers, and create a benign and win-win ecosystem

5. Consolidate leadership and market share in the strong areas where the company currently excels, and observe competitors' responses to unfamiliar markets

6. Use variable QR code technology for marketing, bind each brand product with target users, and use social networks for targeted content marketing

On the basis of building brand competitiveness, this paper uses analytic hierarchy process to build a brand-new brand competitiveness index system. The system is divided into three levels: target level, first-level indicators, and second-level indicators. The first level is to measure the development situation of the L'Oréal Group; the second level is the relative pros and cons. This indicator system takes into account internal and external factors that affect brand competitiveness. At the same time, the analytic hierarchy process, combined with expert scoring and statistical methods, allows each indicator to pass the consistency test to solve the weight of the entire indicator. Therefore, the scientific and applicability of the indicator system is feasible, providing theoretical support for subsequent research. However, the index system of the model still has room for further improvement, especially in the expert scoring link in the comprehensive scoring method, where the subjective influence of experts is relatively large, and the deviation caused by this is inevitable. This is also a point that needs to be broken through in follow-up research. It is hoped that a more scientific and universal comprehensive evaluation index system can be provided for the strategic decision analysis of enterprises in the future.

\section{References}

[1] Mei, X., Sun, D.Y. (2019). L'Oréal: a century of development, a leader in the global beauty industry. HuaTai Securities.

[2] L'Oréal. (n.d.). About L'Oréal.

[3] Thompson, V. (2020). Influence of Advertisement on Women \& the Attitude Toward Cosmetics. CHRON.

[4] HAMILTON, S. T. E. P. H. E. N. F., RICHARDS, T. I. M. O. T. H. Y. J., \& STIEGERT, K. Y. L. E. W. (2011). How does advertising affect market performance? A note on generic advertising. Economic Inquiry, 51(2), 1183-1195.

[5] Harris, H. (2017, November 21). The influence of advertising on business. Small Business - Chron.com. Retrieved October 4, 2021.

[6] L'Oréal. (2020, January 23). L'Oréal group: Strategy \& model.

[7] L'Oréal Finance. (2020). Cosmetics market. L'Oréal Finance: Annual Report.

[8] Bhasin, H. (2018, June 13). Marketing strategy of L'Oréal.

[9] Frue, K. (2018, November 26). SWOT analysis of L'Oréal: A powerful portfolio of brands. PESTLE Analysis.

[10] Š́rová, V. (2015). Managing Marketing Report on L'Oréal Group. CRIS - Bulletin of the Centre for Research and Interdisciplinary Study, 1(1).

[11] Xiao Wang, Jia-qi Dong, Yang Chen, Wen-fu Zheng. Modeling the value creation through business models: Cases study of Estee Lauder and L'Oreal [J]. Helsinki School of Economics, 2014, (9) .

[12] Planning [J]. Journal of Jilin University (Engineering and Technology Edition), 2017, 47 (04): 1055-1060.

[13] Li Xinrui, Qi Zhenhong, Wu Lanya, etc. Modern Chinese Seed Industry Based on AHP

[14] SWOT Analysis of Development [J]. Science and Technology Management Research, 2015, 35 (03): 2227. 
[15] Qu Zuoqi. Research on the International Competition Strategy of Enterprises in the Internet Era[J]. Business News ,2020(03):106-107.

[16] "Operational Research" Textbook Writing Group Operational Research[M]. Beijing: Tsinghua University Press, 2005

[17] Welcome to l'oréal. L'Oréal. (n.d.). Retrieved October 14, 2021, from https://www.loreal.com/.

[18] Fang Ruiwei, Zhang Xiedong, Jiang Pan, et al. Urban rapid traffic based on SWOT-AHP 